\title{
Solid tumours in children
}

\author{
A. E. Claireaux \\ M.D., F.R.C.P., F.R.C.O.G., F.R.C.Path. \\ Professor of Morbid Anatomy, Institute of Child Health, University of London
}

TuMOURs, together with accidents are the major cause of death in children over 1 month of age (Registrar General, 1970). They account for about one-fifth of all deaths between 5 and 15 years of age and for about $10 \%$ thereafter.

In addition to true neoplasms many benign lesions such as naevi and vascular hamartomas of all kinds are very common in children. These are not included in the material under consideration.

Almost one-third of malignancy occurring in children takes the form of leukaemia. This has also been excluded from the present series which is concerned solely with solid neoplasms.

Solid tumours found in patients seen at the Hospital for Sick Children were reviewed fairly recently (Claireaux \& Innes-Williams, 1968) and that series has now been brought up to date (Table 1).

TABLE 1. Tumours 1953-70 inclusive (1303)

\begin{tabular}{lrc}
\hline & No. & Percent \\
\hline Neural origin & 601 & 46 \\
Embryonic & 182 & 14 \\
Mesenchymal & 150 & 12 \\
Teratoma & 95 & 7 \\
Haemopoietic (excluding leukaemia) & 94 & 7 \\
Epithelial & 65 & 5 \\
Skeletal & 43 & 3 \\
Endocrine & 37 & 3 \\
Chordoma and craniopharyngioma & 36 & 3 \\
$\quad$ Total & 1303 & 100 \\
\hline
\end{tabular}

The pattern of neoplastic disease in children differs from that found in the adult. We have already noted that leukaemias account for one-third and neural and neural crest tumours account for a further third. A large proportion of the remainder is accounted for by tumours of an embryonic nature and teratomas. By contrast, the carcinoma of epithelial origin so typical of malignant disease in the adult, is excessively rare in children (Willis, 1962).

The common tumours in children are those whose cell pattern is markedly embryonic in type such as the neuroblastoma, the nephroblastoma (Wilms' tumour), the hepatoblastoma and the embryonic sarcomas of the urogenital sinus.

The tumours in our series comprise material obtained at biopsy during the period 1953-70 and the total is 1303 (Table 1). Tumours of neural origin including the neuroblastoma account for $46 \%$ of the total and the embryonic tumours for a further $14 \%$. Miscellaneous tumours, listed as 'others', include a wide variety of rare tumours such as thymomas, tumours of the ductless glands and carcinoids.

It would not be possible in a single article to give a detailed description of all the solid tumours likely to be found in children and only the major groups of tumours such as the gliomata and the embryonic neoplasms will be discussed in detail.

\section{Tumours of the central nervous system}

These comprise the gliomas, the medulloblastomas, the craniopharyngiomas, tumours of the choroid plexus and meningiomas.

In the child, the majority of gliomas arise beneath the tentorium and at least two-thirds of these tumours are seen in the posterior fossa. By contrast most gliomas in adults occur in the cerebrum.

\section{Medulloblastoma}

This tumour is twice as common in males as in females and $50 \%$ of the tumours arise in the first decade.

The tumours are soft and pinkish-grey in colour. Necrosis is frequent but calcification is decidedly rare. They tend to arise in the mid-line of the cerebellum and may partially obliterate the fourth ventricle. They are liable to seed along the CSF pathway and involve the meninges of the spinal cord. Distant metastasis is very rare. In a few cases the tumour may originate in the cerebrum.

On histological examination the tumour is seen to be very cellular and is composed of sheets of round or oval cells with scanty cytoplasm and dark nuclei (Fig. 1). Differentiation may take the form of rosette formation but this is seldom so pronounced as in neuroblastoma or retinoblastoma. In a few cases the cells are arranged in islands (Fig. 2). This last variant seems to carry a better prognosis than that of the completely undifferentiated tumours.

\section{Gliomas}

The cystic astrocytoma arising in the cerebellum is one of the commoner tumours affecting the brain 




Fig. 1. H \& E. Medulloblastoma. Undifferentiated sheets of small dark cells.

in children. It tends to be well demarcated from the neighbouring normal tissue and not infrequently is easily shelled out.

Whereas the cerebellar medulloblastoma is usually found in very young infants the astrocytoma is infrequently seen under the age of 2 years.

The tumour is cystic and the spaces may contain yellow-brown fluid. On histological examination microcysts are evident and the tumour shows marked degenerative change (Fig. 3).

Less well circumscribed astrocytomas may occur anywhere in the brain or spinal cord. Not infrequently they develop in the region of the third ventricle and the prognosis is less good than in the localized cerebellar variety.

Subependymal gliomas arising close to one of the ventricles are not uncommon in children. The cells comprising the tumour extend towards the ependyma lining a ventricle but are not of ependymal origin. True ependymomas also occur. The fourth ventricle is a frequent site of origin and the tumours tend to seed themselves along the spinal cord. In a few instances the tumours may arise at the lower end of the cord itself.

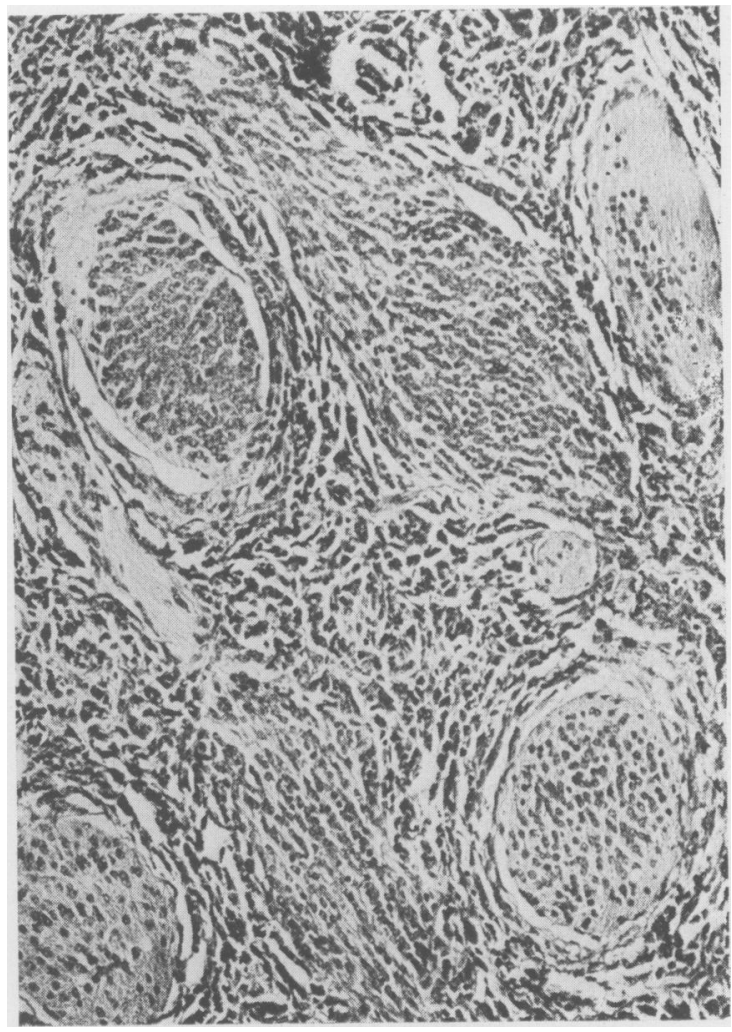

Fig. 2. H \& E. Medulloblastoma. Islands of partially differentiated cells.

\section{Retinoblastoma}

This form of tumour tends to affect infants and young children. One or both eyes may be involved. In some cases more than one sibling in a family may be affected and in such instances the condition is inherited by a dominant gene.

The tumour arises in the posterior half of the retina and as it enlarges it comes to occupy all or most of the posterior chamber of the eye. Extension may occur into the orbit along the optic nerve. More widespread metastasis to cervical lymph nodes or via the blood stream to the skeleton is rare.

The tumour is composed of oval darkly-staining cells some of which show a very marked rosette formation (Fig. 4). The cells in these rosettes are arranged radially to an internal limiting membrane, and are believed to represent attempts on the part of the tumour cells to form rods or cones. Elsewhere the tumour may show areas of necrosis or calcification.

If the tumour, after surgical removal, is seen to be confined to the globe about half the patients will survive. In a proportion of cases spontaneous regression of the tumour has been recorded. Such 


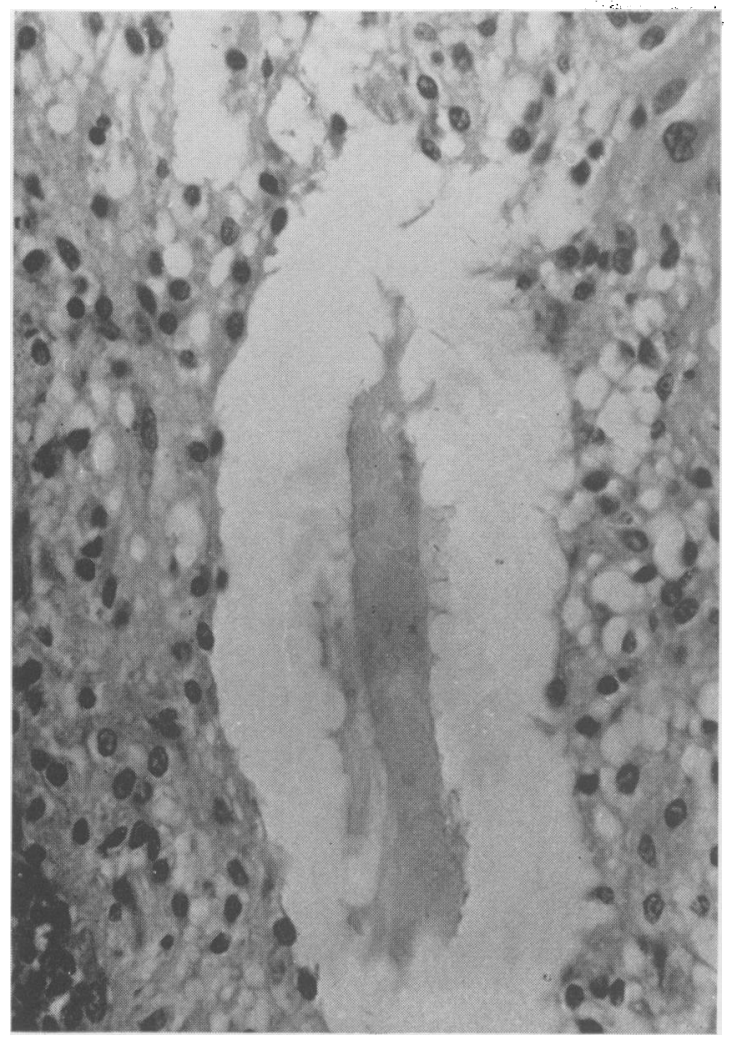

FIG. 3. H \& E. Cystic astrocytoma. Areas of degeneration.

regression is more frequently seen if one eye has already been removed for retinoblastoma.

\section{Diktyoma}

This tumour, sometimes known as a medulloepithelioma, is much less common than the retinoblastoma. It customarily arises in the ciliary body and has a characteristic histological appearance (Fig. 5). The cells are epithelial in type and arranged in a fine network. Some of the cells may be markedly pigmented.

\section{Craniopharyngioma}

These tumours are suprasellar cysts arising from squamous cell nests in the parapituitary region. They are not uncommon in children and accounted for some $2 \%$ of our tumour material. These tumours are partly cystic and partly solid. Calcification frequently occurs and may be very extensive. When the cysts become large they bulge into the wall of the third ventricle and hydrocephalus may develop.

On slicing, the cystic spaces contain brownish fluid which is loaded with cholesterol crystals. The cysts are lined by squamous epithelium and the wall

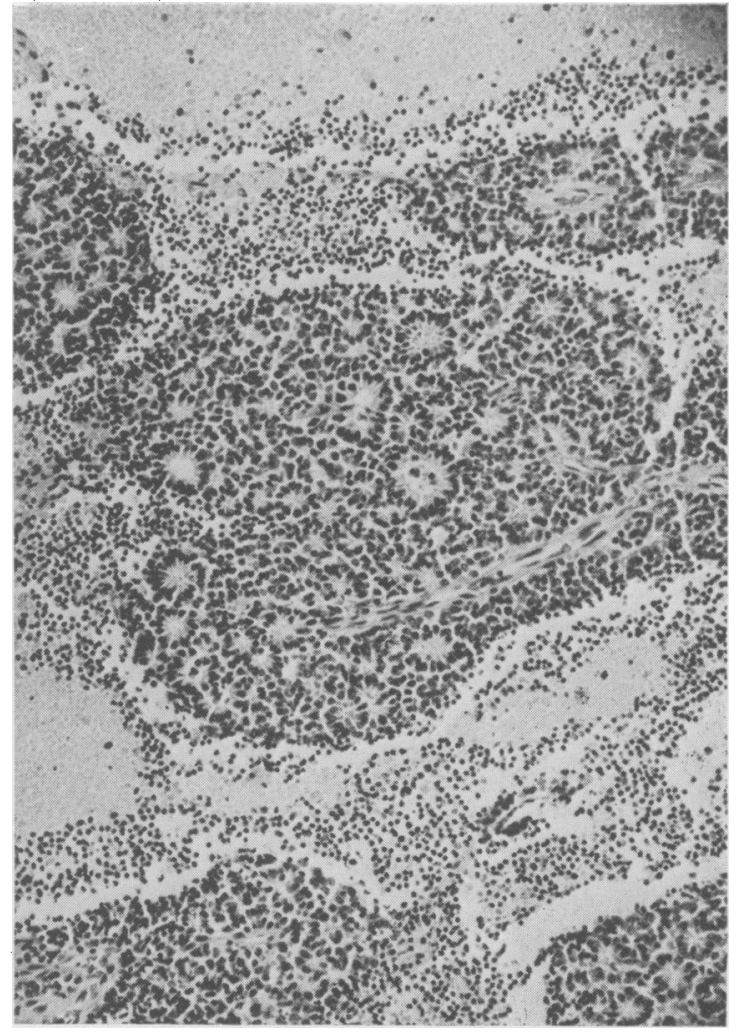

FIG. 4. H \& E. Retinoblastoma. Rosette formation.

is composed of connective tissue. Degenerative changes are widespread in the epithelial component and this leads to cyst formation. Whorls of keratin become hyalinized and eventually calcify. The stroma shows myxomatous change and microcyst formation occurs (Fig. 6). The tumours do not metastasise but complications from pressure do occur.

\section{Neuroblastoma}

This is one of the commoner malignant tumours in children and accounts for $13 \%$ of our material. The tumours are of neural crest origin and may occur in the adrenal medulla or sympathetic chain. They may appear in the neck, thorax, adbomen or pelvis. The tumour is encountered most frequently in children under 3 years of age and quite well developed tumours are sometimes found in the foetus and newborn infant.

The clinical features are non-specific and include vomiting, loss of weight and anaemia. Pain is a feature if deep infiltration has occurred. When the tumour arises in the sympathetic chain a dumb-bell like extension may occur into the extradural space. Spinal cord pressure will result in weakness of the 


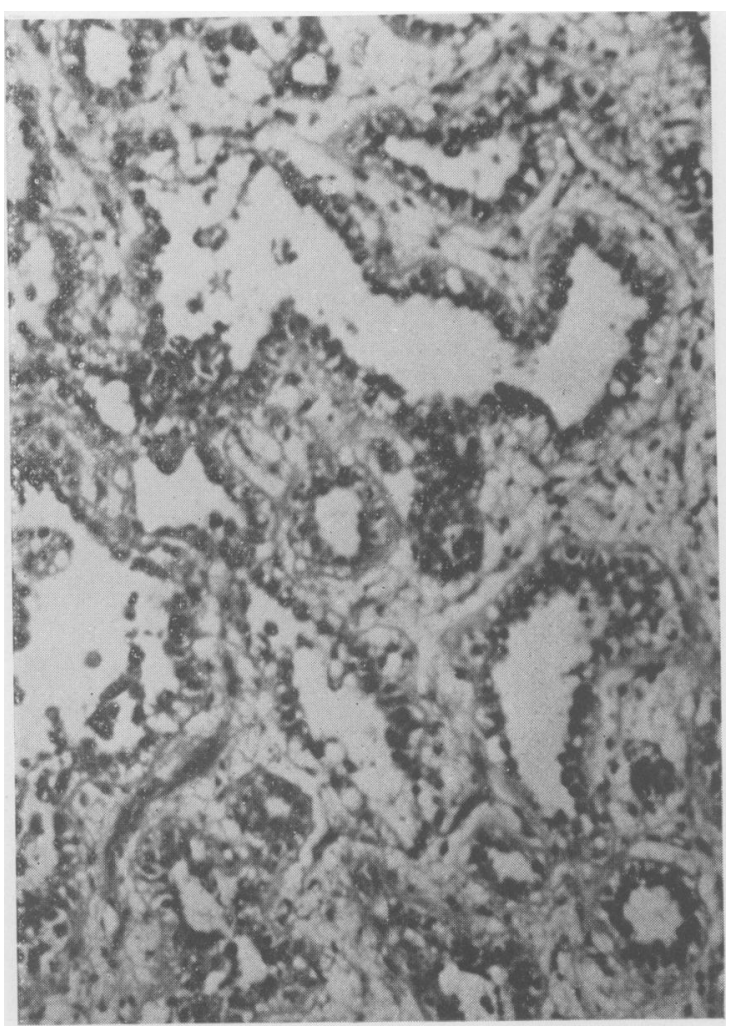

FIG. 5. H \& E. Diktyoma. Network of strands of epithelial cells.

limbs and paraplegia. Tumours arising in the pelvis may cause urinary obstruction.

More frequently the tumour arises in the abdomen and presents as a lobulated mass extending back into the loin. It may at times be difficult to establish whether the tumour is of renal or extrarenal origin but routine abdominal radiograph and pyelogram will help to distinguish it from the almost equally common nephroblastoma. Calcification is usually a prominent feature in the neuroblastoma, especially those of adrenal origin and an intravenous pyelogram will show downward displacement of the kidney. If the tumour has arisen in the sympathetic chain it may distort the ureter and cause hydronephrosis. A complete skeletal survey is also mandatory as bone metastases are common in neuroblastoma. Smears from sternal marrow may also reveal neuroblastoma cells. A number of neuroblastomas are chemically active and certain metabolites such as 3 methoxy -4 hydroxy mandelic acid (VMA) may be excreted in the urine in increased quantities. This occurs in about half the cases.

In addition to skeletal metastases the tumour

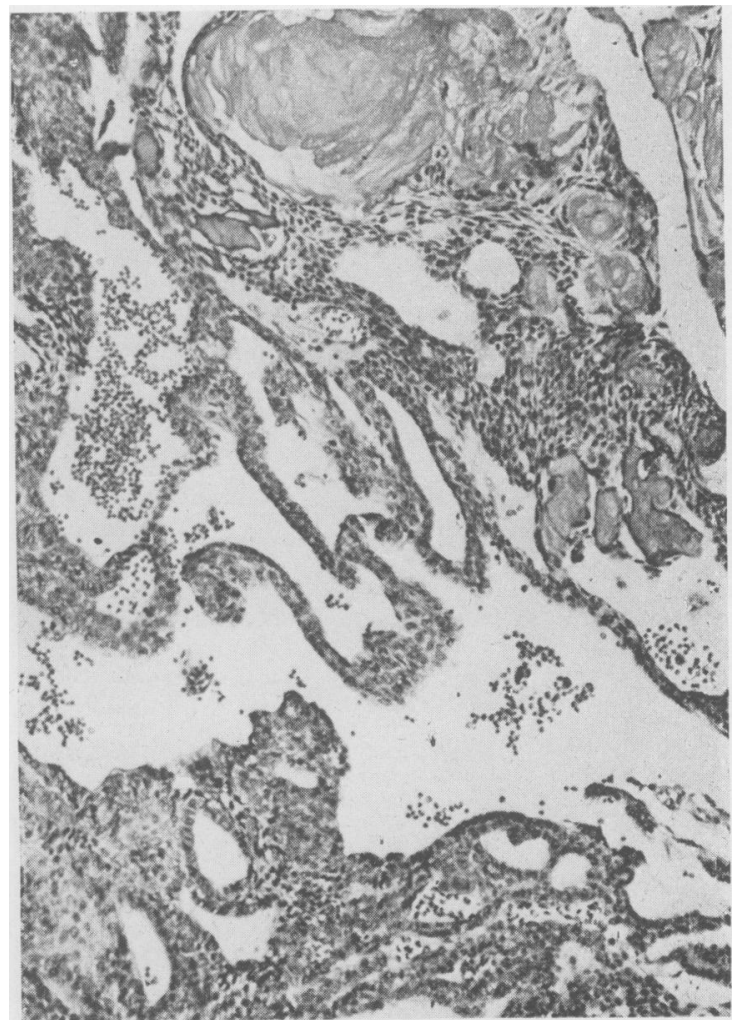

FIG. 6. H \& E. Craniopharyngioma. Degeneration and calcification.

may spread widely to lymph nodes and other organs, particularly the liver.

The outcome of the disease as far as the patient is concerned depends mainly on the age at onset, the site of the primary tumour and the presence of radiologically demonstrable skeletal deposits. Tumours arising in the neck or thorax run a more benign course than those of abdominal, especially adrenal, origin. Spontaneous regression is known to occur but is almost always confined to patients under the age of two years when first seen. Spread of the tumour beyond the primary site, even multiple metastases in the liver are not necessarily hopeless signs in the young infant. Multiple skeletal metastases on the other hand almost invariably lead to a fatal termination.

The tumours are often large and have a pinkishgrey lobulated appearance. Areas of haemorrhage, necrosis and calcification are frequent. On histological examination the mass is composed of sheets of small round, darkly-staining cells with scanty cytoplasm and prominent nuclei. The cells may have a trabecular arrangement and intervening bands of connective tissue carry blood vessels (Fig. 7). Many 


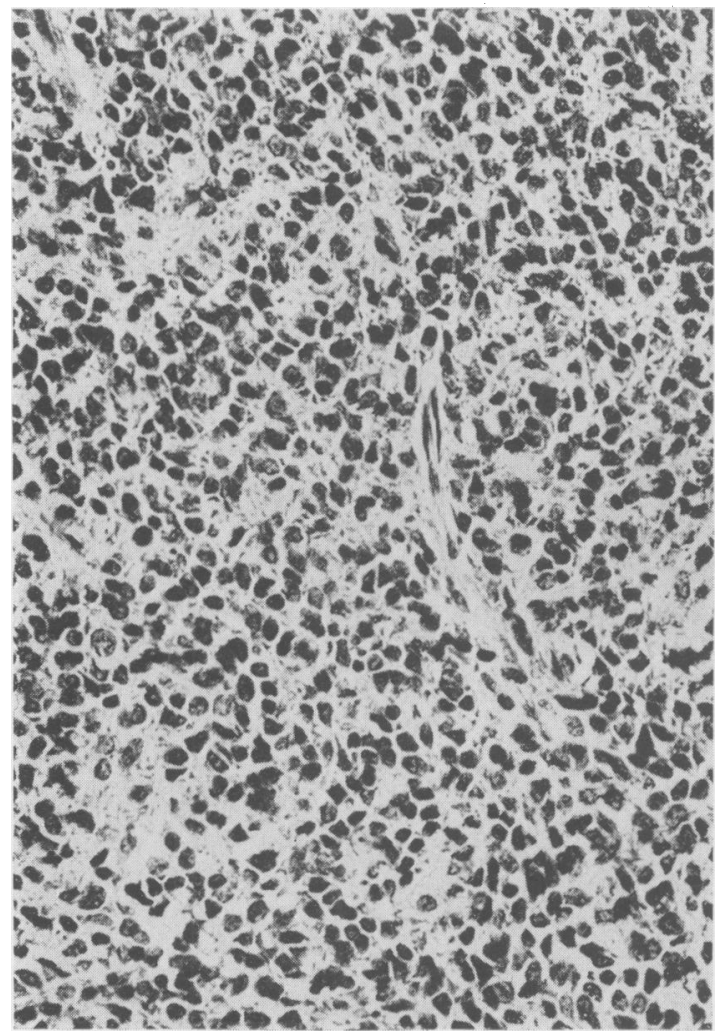

Fig. 7. H \& E. Neuroblastoma. Sheets of small round cells.

tumours are completely undifferentiated but some show slight or even marked attempts at differentiation. Early maturation is indicated by rosette formation where the cells are arranged peripherally around acidophil fibrillary material (Fig. 8). Further differentiation is indicated by the presence of large pro-ganglia and some tumours are designated 'ganglioneuroblastomas'. The behaviour of such 'mixed' tumours depends on the neuroblastomatous element.

Complete differentiation is seen in the ganglioneuroma which is a benign tumour composed of ganglion cells, nerve bundles and connective tissue (Fig. 9).

It is not clear whother spontaneous regression of the neuroblastoma is accompanied by maturation to ganglioneuroma or whether necrosis and ultimate disappearance of the tumour is responsible. It is possible that both modes of regression can occur. Such regression is unlikely in the older child but is not uncommon in those patients under 1 year of age who do not have multiple skeletal metastases. The biological behaviour of the neuroblastoma is unlike that of most other solid tumours in children.

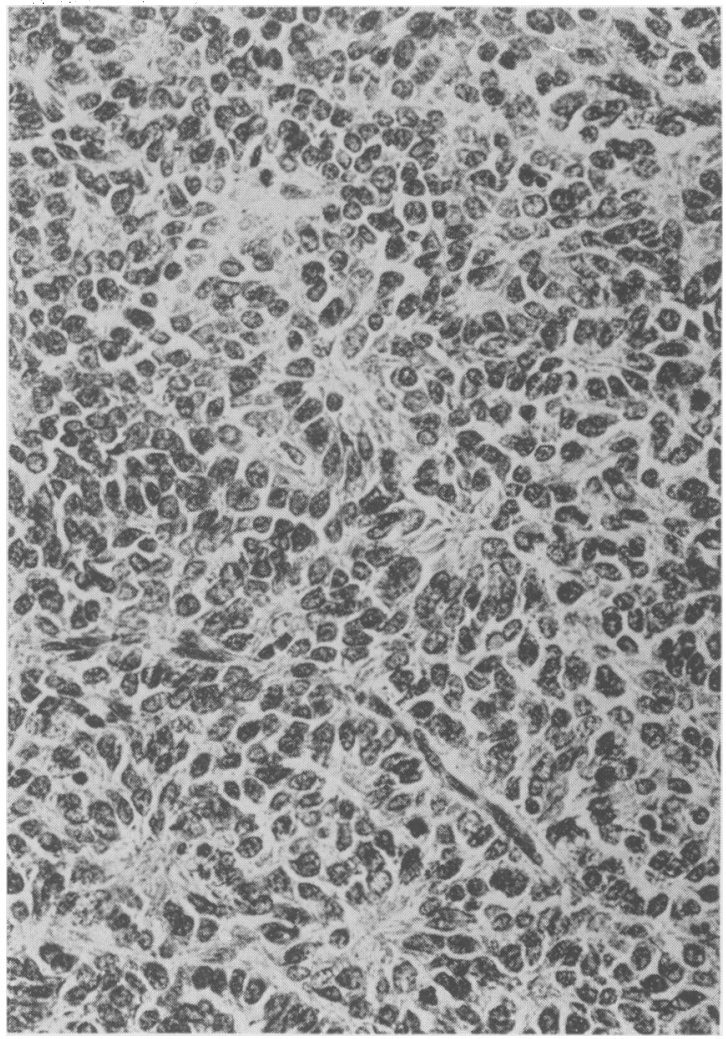

FIG. 8. H \& E. Neuroblastoma. Rosette formation.

\section{Embryonic tumours}

Many tumours in this category present in the abdomen. Unlike the adult, the child rarely exhibits neoplastic disease in the gastro-intestinal tract. The abdominal organ most frequently affected is the kidney and the tumour is the nephroblastoma. Other embryonic tumours are the hepatoblastoma arising in the liver and the embryonic sarcoma (rhabdemyosarcoma) arising in organs derived from the urogenital sinus.

\section{Nephroblastoma}

This tumour arising in the renal parenchyma is sometimes called a Wilms' tumour (Wilms, 1899) although it was described some 70 years before that author's publication.

The tumour is usually unilateral but both multiple and bilateral variants are described. They are often very large and may weigh several hundred grams. On slicing, some flattened, surviving renal tissue may be found along one edge of the tumour. Necrotic areas are common and cyst formation is not infrequent (Fig. 10). The histological appearance varies considerably, not only from case to case, but 


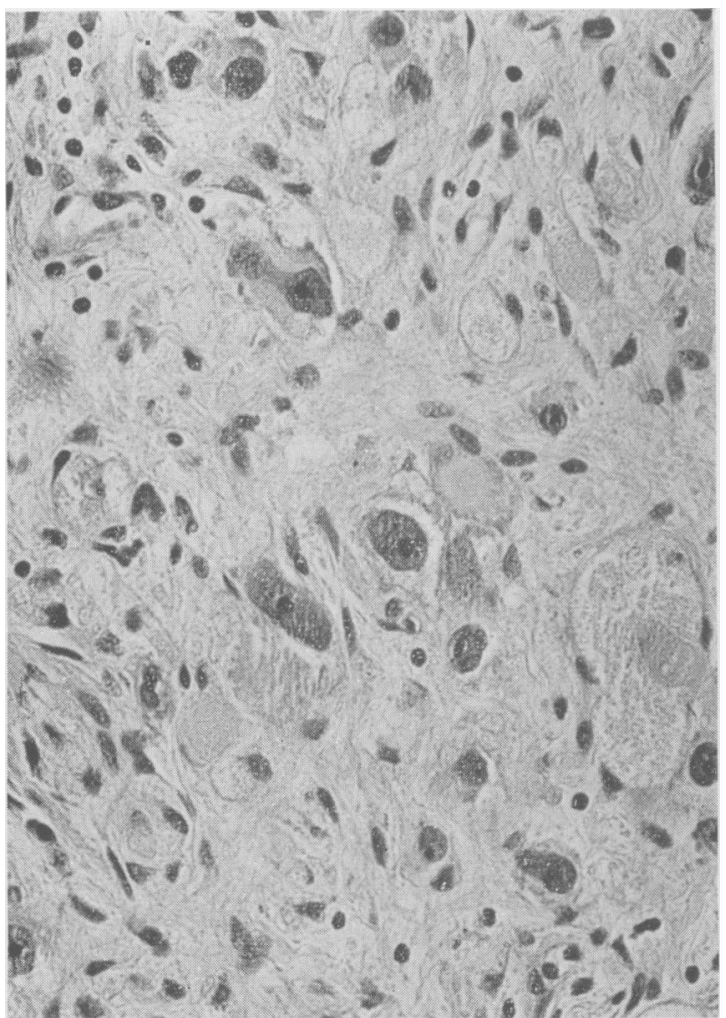

Fig. 9. H \& E. Ganglioneuroma.

in the individual tumour. Some show little in the way of recognizable renal tissue and are composed of sheets of renal blastema separated by varying amounts of a primitive mesenchyme (Fig. 11). Other tumours may have clumps of tubules or even attempt

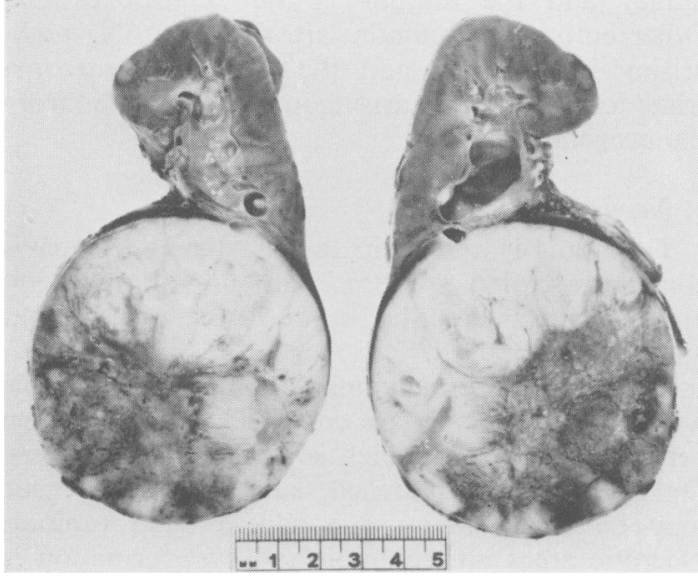

FIG. 10. Nephroblastoma.

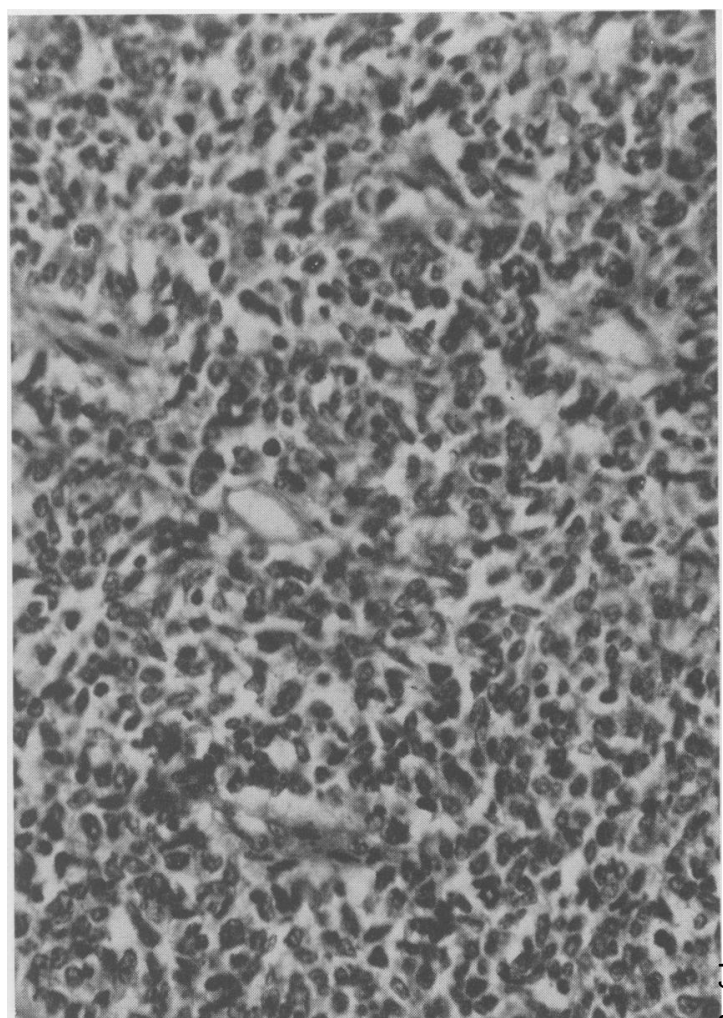

Fig. 11. HI\& E. Nephroblastoma. Primitive renal blastema.

glomerular formation (Fig. 12). Many of the tumours which are markedly cystic show papilliferous change under the microscope. Others are mainly mesenchymal and contain sheets of connective tissue, muscle, cartilage or even bone.

The tumour tends to invade the renal veins and metastasizes via the blood stream to the lungs, liver and skeleton. The histological appearance of the metastases, which are commonest in the lungs, may differ widely from that of the primary tumour.

The tumours occur mainly in young children and the peak incidence is in the second year of life.

\section{Fibrous tumour of kidney in infants}

Although the nephroblastoma is common in young children it is seldom found at birth or in the very young infant. This is in contrast to the neuroblastoma where 'congenital' tumours are not so uncommon. So-called congenital nephroblastomas are usually tumours of the kidney composed almost entirely of fibrous tissue and often containing bizarre blood vessels (Fig. 13). These are really not true neoplasms but hamartomas of the kidney. They are benign, do not metastasize and do not recur after 


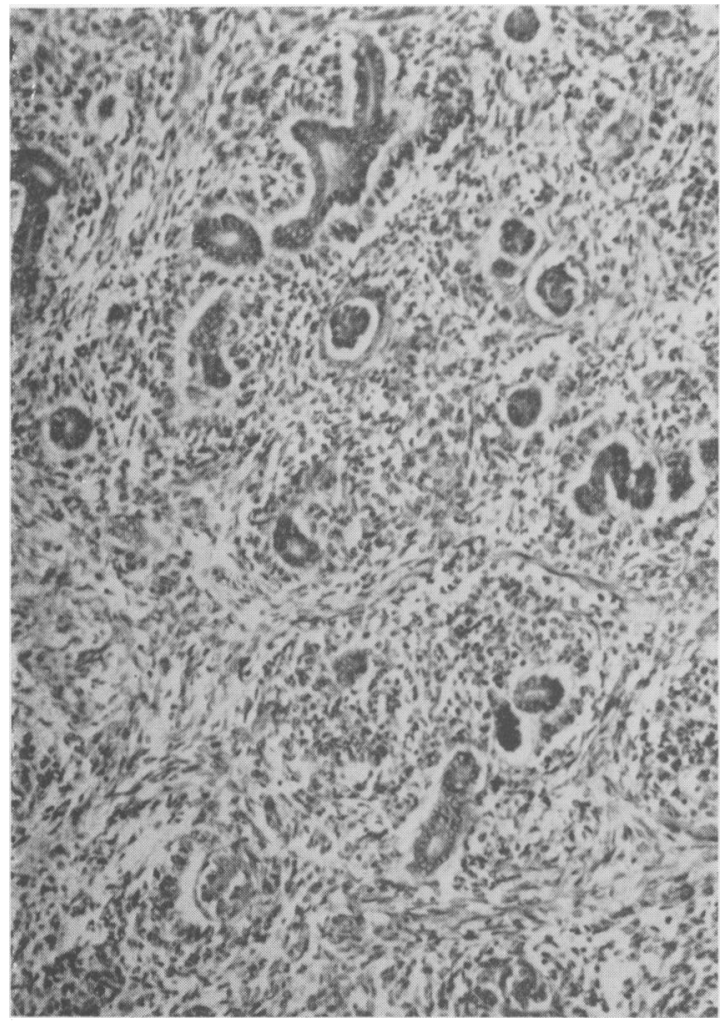

FIG. 12. H \& E. Nephroblastoma showing differentiation.

simple removal of the affected kidney. Fatal results with this tumour are attributed to treatment with actinomycin $\mathbf{D}$. This drug is unnecessary in the fibrous hamartomas and a correct diagnosis is vital.

\section{Hepatoblastoma}

This tumour is less common than the nephroblastoma and has been reviewed by Nixon (1960). This embryonic hepatic neoplasm occurs during the first 3 years of life and the liver tumour found in older children is usually a carcinoma.

The liver tends to enlarge rapidly and may reach an enormous size. On slicing, the normal parenchyma is seen to be replaced by nodules of tumour (Fig. 14). The mass is composed of small oval cells resembling foetal liver cells (Fig. 15). Like the nephroblastoma, 'mixed tumours' occur where, in addicion to small liver cells, muscle, osteoid and bone may be encountered (Fig. 16).

Much less frequently the liver is affected by an embryonic sarcoma of botryoid type similar to that occurring in the urogenital sinus.

The hepatoblastoma is highly malignant and may metastasize widely. If confined to one lobe of the liver

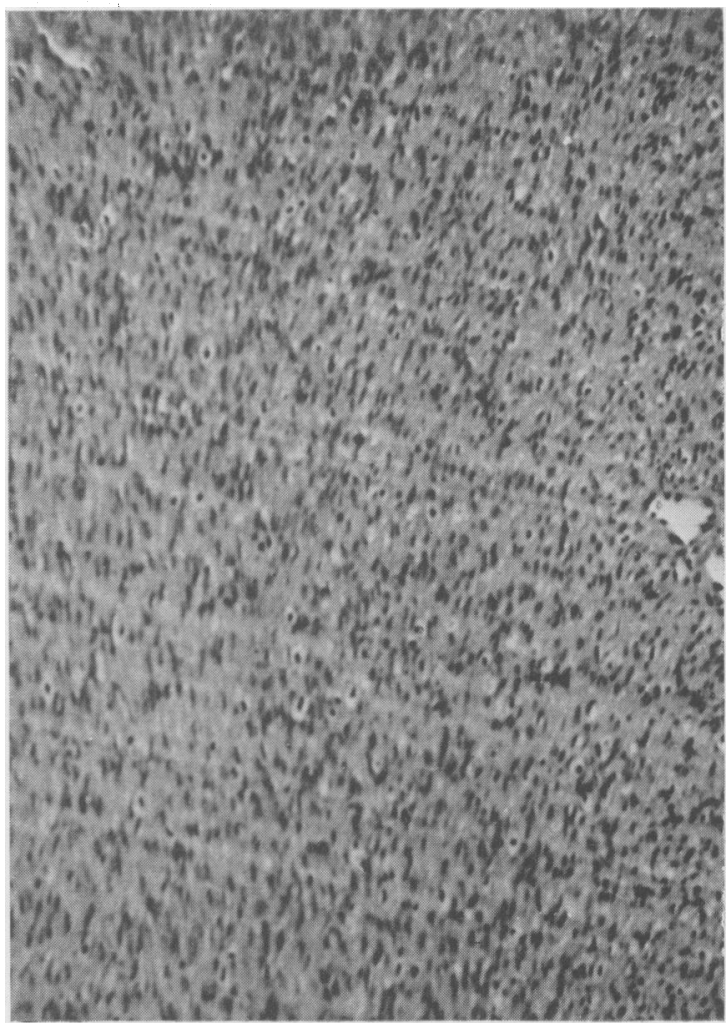

FIG. 13. H \& E. Hamartoma of kidney.

when first seen, a partial hepatectomy may effect a cure.

\section{Hamartoma of the liver}

These are not uncommon in the foetus and newborn. They usually affect one or other lobe and cause hepatic enlargement. Less commonly the lesion is diffuse. They are formed of haemangiomatous tissue and huge cavernous spaces liable to rupture at the time of birth may be found. These in turn can result in an enormous vascular shunt and some infants present as hydrops foetalis.

\section{Rhabdomyosarcoma (embryonic sarcoma)}

These tumours arise in certain sites, notably in structures arising from the urogenital sinus or around the head and neck, in the orbits, ear and pharynx. These embryomatous tumours tend to differentiate towards striped muscle. These tumours are resistant to both radiotherapy and most chemotherapeutic agents so that radical surgery prior to the occurrence of metastasis offers the best prospect of a cure. The tumours have their peak incidence in the first 3 years of life. 


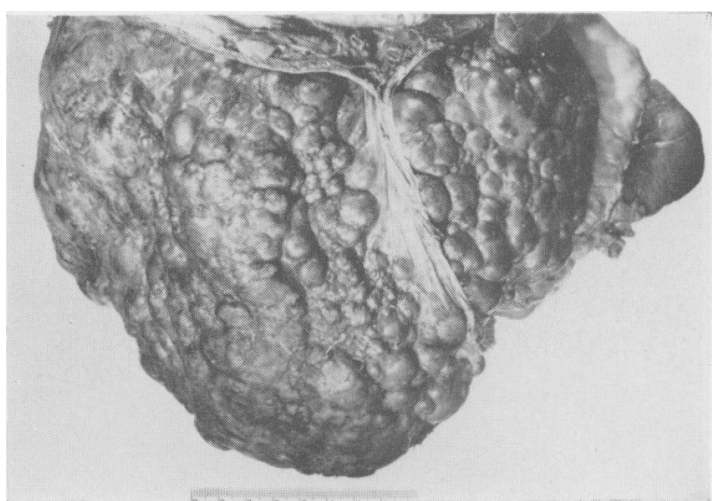

Fig. 14. Hepatoblastoma.

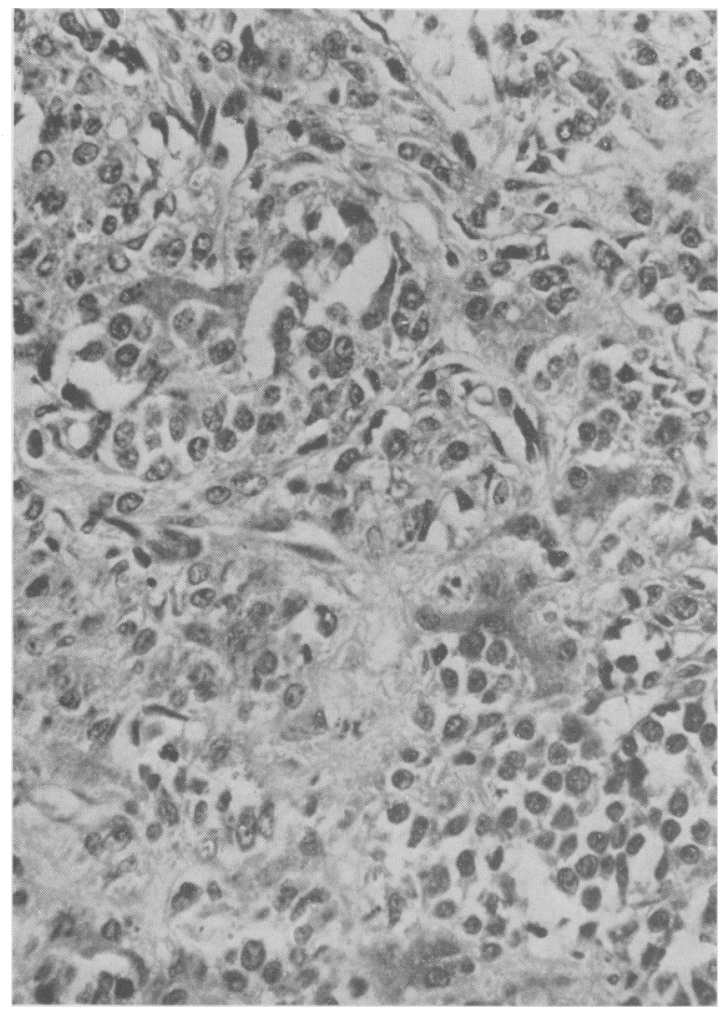

Fig. 15. H \& E. Hepatoblastoma. Foetal cell type.

When the tumour arises in the female it may fill the bladder and vagina with gelatinous nodules which sometimes appear at the vulva. This form of tumour is known as sarcoma botryoides (Taylor, 1968). This form of embryonic sarcoma is seen in very young infants and is uncommon after the second year of life.

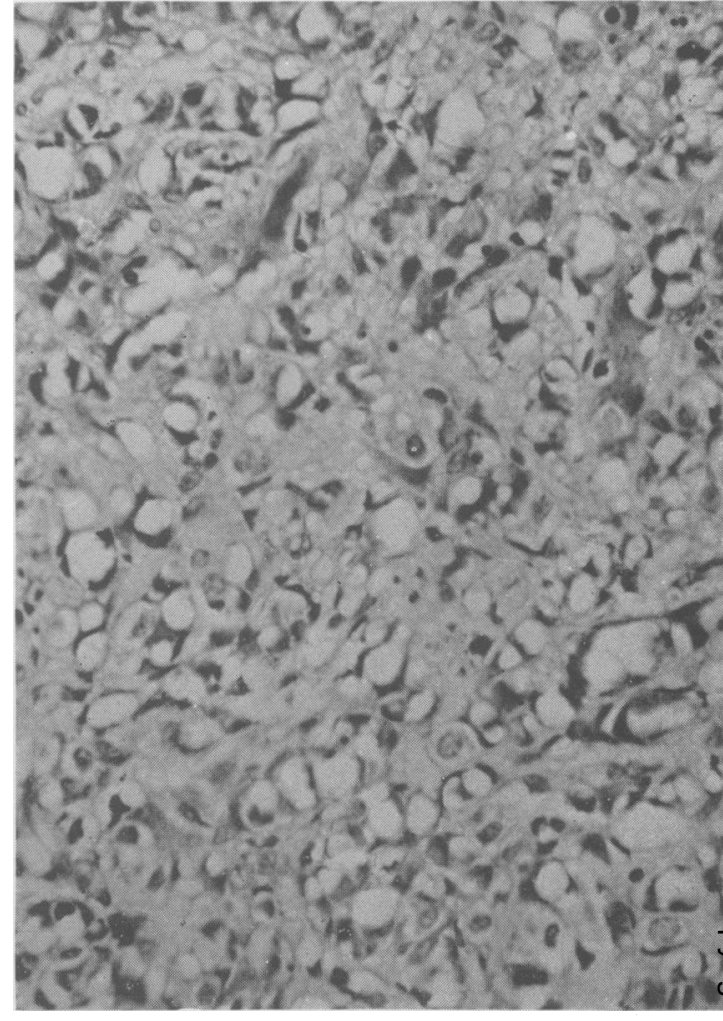

Fig. 16. H \& E. Hepatoblastoma. Mixed type.

The upper anterior vaginal wall is the chief site of origin. The tumour commonly invades the bladder but uterine involvement is rare. The tumour nodules are composed of soft, myxomatous tissue clothed by epithelium (Fig. 17). This epithelium is squamous if the nodules are in the vagina and transitional if the bladder is the site of origin. Beneath this epithelium the loose myxomatous tissue contains clumps of cells which are pleomorphic in character. Long straplike or 'tadpole' cells may be seen and some show cross-striations (Fig. 18).

In the male, similar tumours may arise in the bladder, urethra or prostate and less frequently in the epididymis or spermatic cord. The tumours tend to spread outwards into the pelvis, to the regional lymph nodes and via the blood stream to the lungs.

In the head and neck the tumours arise in the nasopharynx, palate, orbit, ear or parotid region. Those of nasopharyngeal origin are likely to be polypoid in character. In other areas they tend to be diffuse, spread rapidly and have a bad prognosis. Reference has already been made to the very rare form which may originate in the liver. 


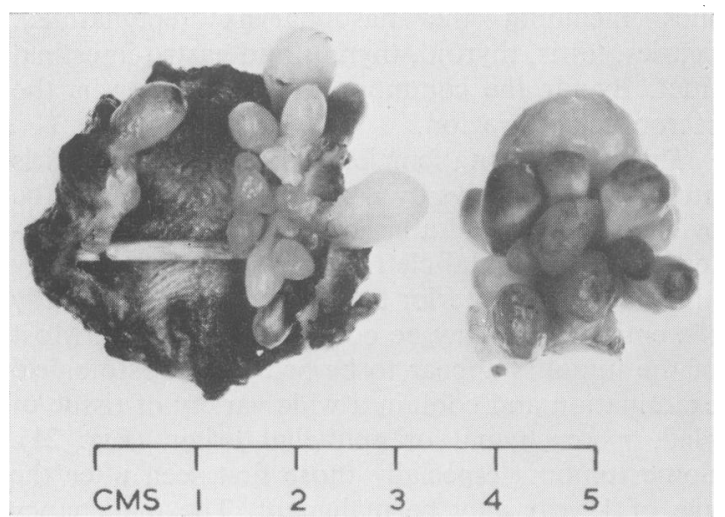

FIG. 17. Sarcoma botryoides. Nodules of tumour tissue.

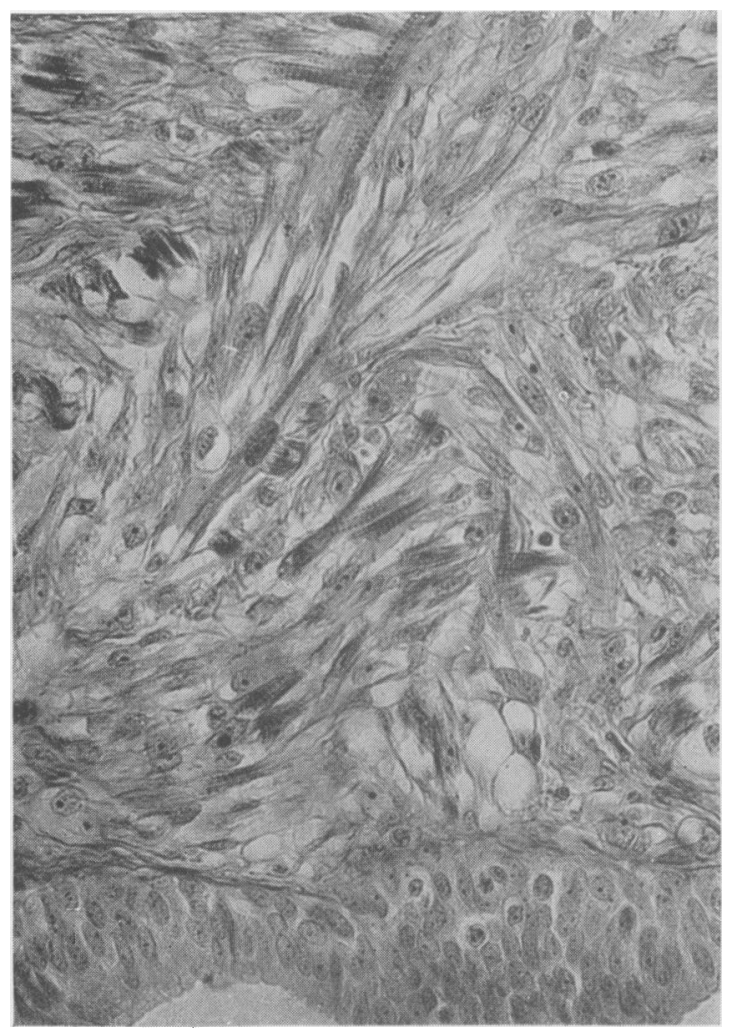

Fig. 18. PTAH. Embryonic sarcoma. Strap-like cells showing cross-striations.

\section{Mesenchymal tumours}

These comprise mainly the fibromas, fibrosarcomas and neurofibromas.

\section{Fibromas}

An unusual, but important, tumour is the fibroma or hamartoma of the kidney which has already been described.

Fibromas may arise almost anywhere and vary considerably in cellularity (Fig. 19). The most important group are the so-called fibromatoses of infancy. These may arise in proximity to tendon aponeuroses in the hands and feet and especially in the buttocks. The tumours are composed of highly cellular fibrous tissue and mitoses are frequent. They tend to spread widely and have an unfortunate tendency to recur locally when the original mass is removed surgically. They do not however, metastasize.

\section{Fibrosarcoma}

This is a comparatively rare tumour in children and only $3 \%$ of our fibrous tumours metastasized. The fibrosarcoma is composed of rather a wild densely cellular tissue and mitoses both normal and bizarre are frequent.

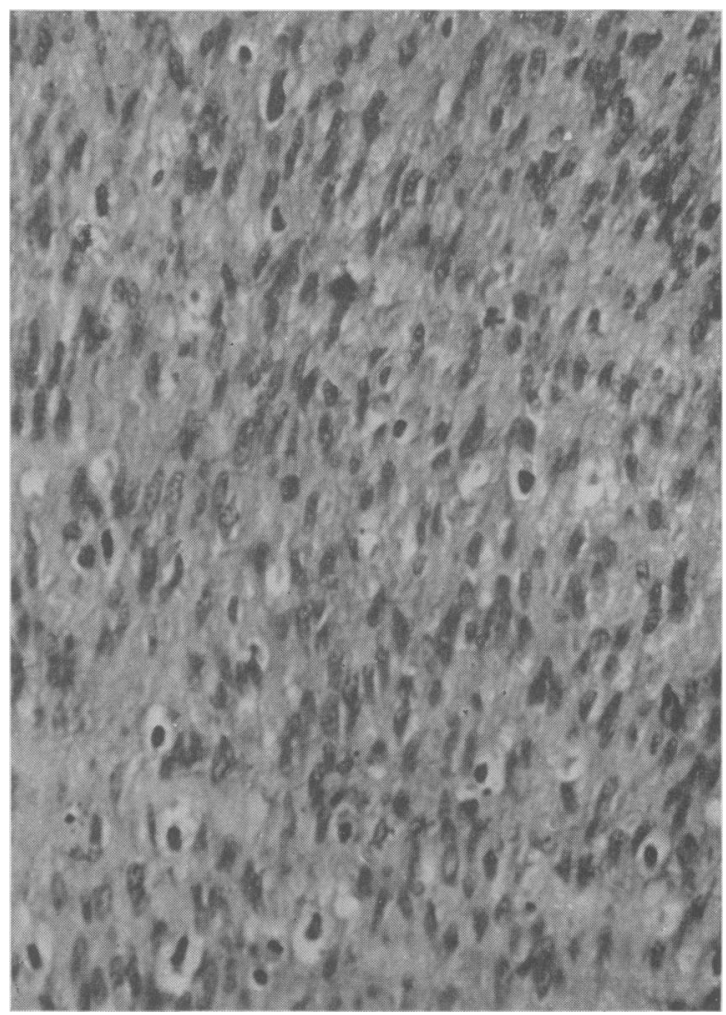

Fig. 19. H \& E. Fibroma. Highly cellular fibrous tissue. 


\section{Neurofibroma}

This is a tumour involving nerve trunks and may arise anywhere in the body and even in bone. On histological examination they are composed of whorled bundles of nerve fibres and connective tissue (Fig. 20). Some reach a considerable size and may undergo myxomatous or malignant change.

\section{Neurofibromatosis (Von Recklinghausen's disease)}

This is a familial disorder where the patient develops multiple neurofibromas and lesions are evident in the skin. The skin lesions take the form of pigmented 'cafe-au-lait' spots. The neurofibromas undergo sarcomatous change in about $10 \%$ of cases.

\section{Teratomas}

These comprise $7 \%$ of our material. They are tumours derived from all three germinal layers and comprise a wide variety of structures. The latter include glial elements, muscle, epithelium of various kinds, cartilage and bone. Some of the structures are of a primitive embryonic type and liable to become invasive. The tumours may arise in many different

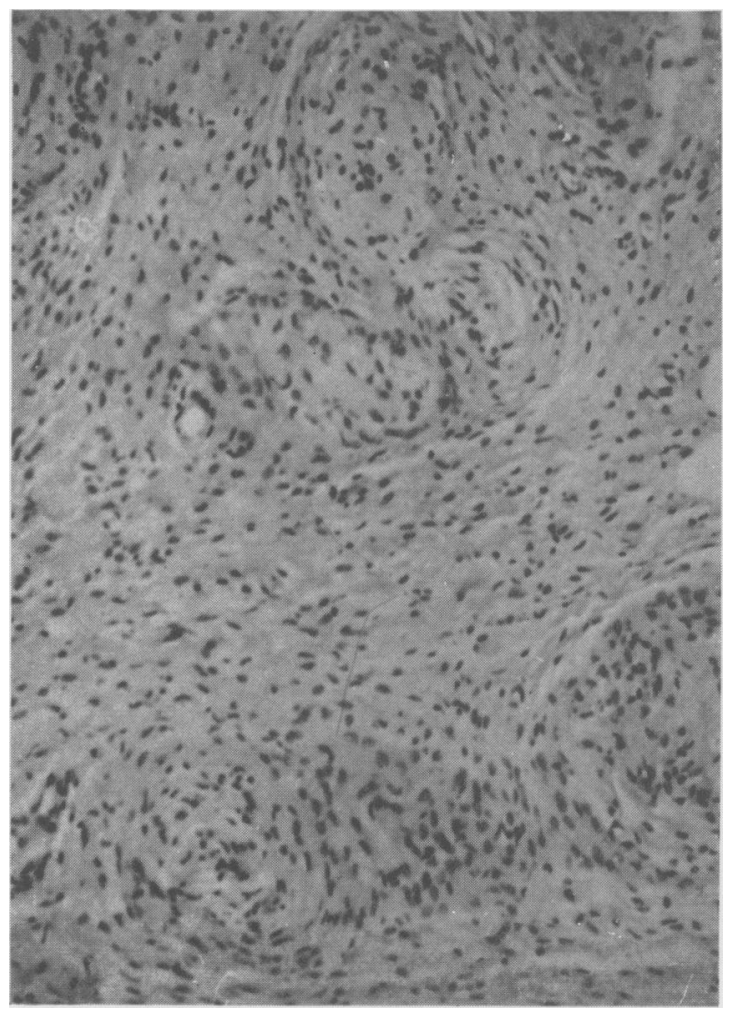

Fig. 20. H \& E. Neurofibroma. Whorled bundles of fibres. sites including the nasopharynx (epignathus), ovaries, testis, thyroid, thymus and gastro-intestinal tract. By far the commonest site, however, is the sacrococcygeal region.

There is a strong female preponderance and girls outnumber the boys by $4: 1$. The tumour may be evident at birth and a large mass may be visible externally in the natal cleft. Some tumour tissue may also be present anterior to the sacrum. Occasionally the entire pelvis may be occupied by tumour. Most of the tumours appear to be benign on histological examination and contain a wide variety of tissue of glial, mesenchymal or epithelial origin (Fig. 21). Some tumours especially those first seen after the age of 1 year may be malignant. The malignancy seems to affect the epithelial structures of the tumour and the appearance is often that of a rather bizarre carcinoma or resembles the embryonal carcinoma of testis or ovary.

When a teratoma arises in the thorax it may be intrapericardial in situation (Claireaux, 1951). More commonly such tumours arise in the anterior mediastinum, are usually benign, and can be removed surgically.

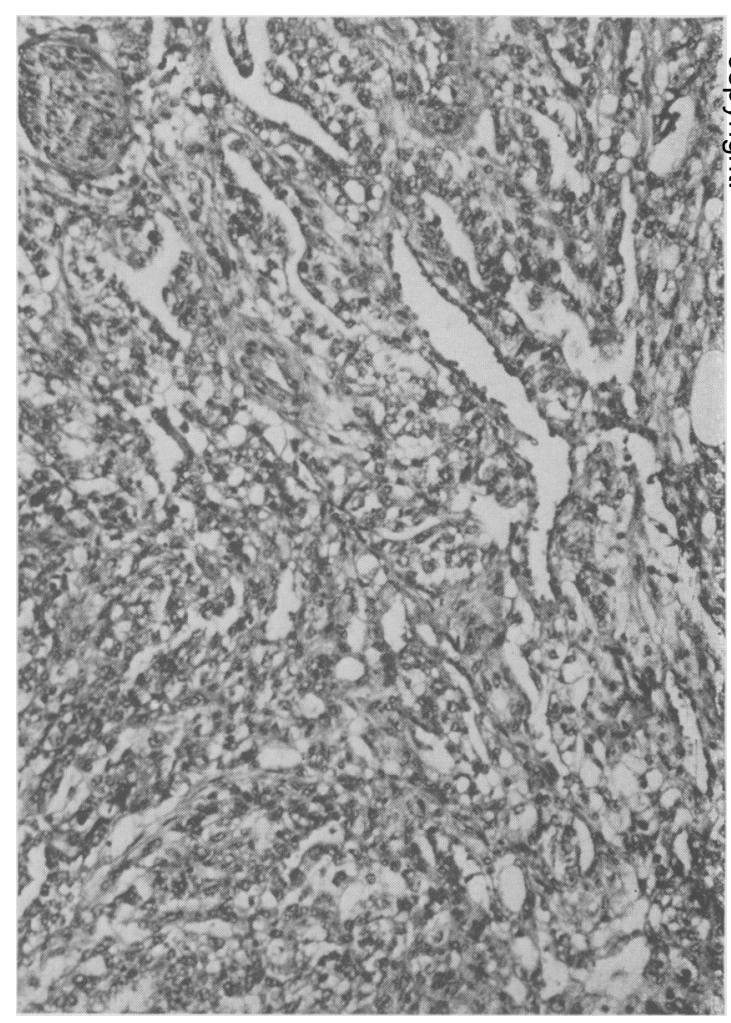

FIG. 21. H \& E. Teratoma. 
Teratomata of the gastro-intestinal tract are uncommon, but such tumours of the stomach have been reported in male children (Atwell, Claireaux \& Nixon, 1967), and have been treated by partial gastrectomy.

Teratomas of ovary or testis are less rare. In the ovary the tumours are mainly benign and occur as 'dermoid cysts'. In the testis they are usually detected before the age of 2 years (Bodian \& White, 1952) and are also usually benign. Occasionally malignant change is seen in teratomas of the testis in the older child.

\section{Reticulo-endothelial tumours}

Neoplastic disease affecting the reticulo-endothelial system is, of course, typified by the leukaemias. Solid tumours affecting this system include lymphosarcoma, lymphoma (Hodgkin's disease) and the reticulo-endothelioses such as histiocytosis $\mathrm{X}$.

\section{Lymphosarcoma}

This lesion may be confined to lymph nodes in the neck, axillae or groin or may arise in the lymphoid tissue of the hand. Lymphosarcoma of the small intestine may invade the submucosa over a wide area and the overlying mucosa tends to ulcerate. The normal lymph node architecture is destroyed and replaced by sheets of round cells with hyperchromatic nuclei and clear cytoplasm. In many cases the cell is indistinguishable from the mature lymphocyte. In others, the cells are larger and have a lymphoblastic appearance. Mitoses are frequent. In still other instances the cells are primitive reticulum cells and the condition may be properly regarded as a reticulum cell sarcoma.

The lymphosarcoma may spread widely to involve more and more lymphatic tissue and in a few instances the disease terminates with a leukaemic phase. As in leukaemia, remissions do occur and the condition may gradually deteriorate over a period of years rather than months.

\section{Lymphoma (Hodgkin's disease)}

This disease is very rare under the age of 4 years. There is a strong male preponderance and the clinical course is variable. Some children die within a few months of onset; others may survive well into adult life.

Lymph nodes in the neck, axillae or mediastinum are more frequently affected than other groups of nodes. The lymph node architecture is disrupted but the cell pattern is more pleomorphic than that of lymphosarcoma. In addition to reticulum-cell proliferation, the disease is characterized by the presence of Reed-Sternburg cells (Fig. 22). These are giant cells derived from reticulum cells. There is a bilobed nucleus with prominent nucleolus surrounded by a variable amount of cytoplasm. The

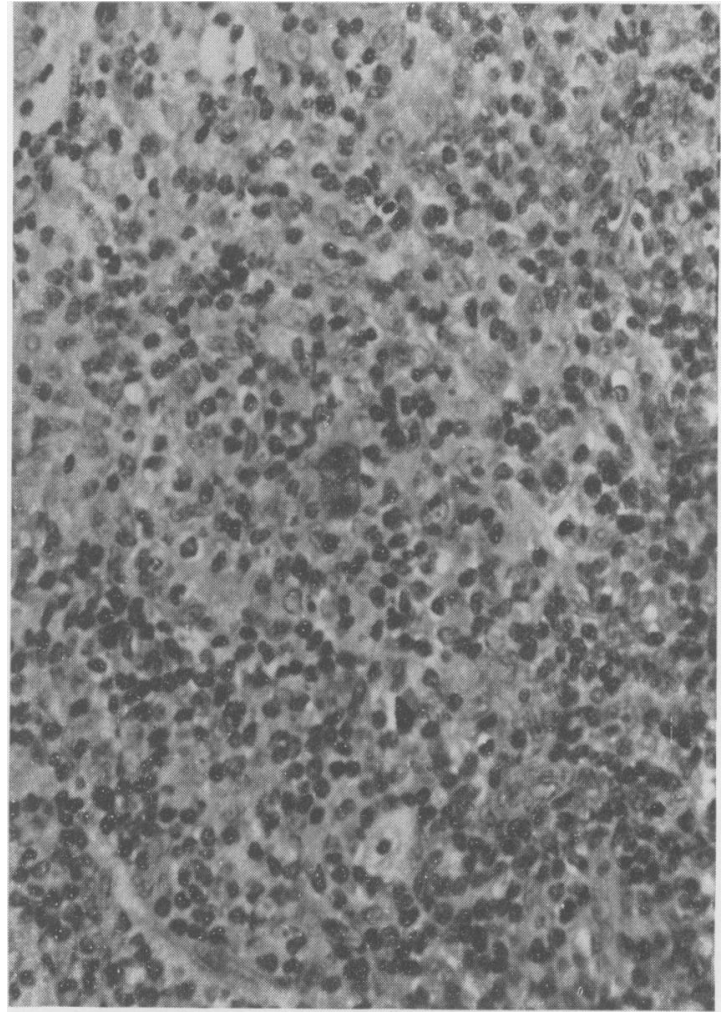

FIG. 22. H \& E. Hodgkin's disease. Reed-Sternberg cell.

presence of such cells are essential for the diagnosis of Hodgkin's disease. Eosinophils may also feature prominently and in cases of longer standing, a large part of an affected node may undergo fibrosis. In a few instances the disease process may be so rapidly progressive that the term Hodgkin's sarcoma is sometimes used.

\section{Histiocytosis $X$}

This form of reticulo-endotheliosis comprises Letterer-Siwe disease, Hand-Schuller-Christian disease and eosinophilic granuloma.

Letterer-Siwe disease. This is a somewhat rare disease affecting infants. It is characterized by fever, skin lesions, lymphadenopathy, hepatosplenomegaly and not infrequently infiltrative lesions in the lungs and bone marrow. On histological examination the lesions are seen to be composed of sheets of histiocytes, some of which may have a foamy appearance, and a variable number of eosinophils. In solid organs the lesions sometimes have a granulomatous appearance. Examination of skin papules or of the bone marrow is usually more helpful than a lymph 
node biopsy as the appearance of the latter is sometimes equivocal.

Hand-Schuller-Christian disease. This has many of the features of the above condition, but bone lesions, especially skull lesions, are more striking. Deposits may occur in the orbits and give rise to exophthalmos and parapituitary deposits to hypophyseal symptoms. The histological appearance shows a far greater proportion of foam cells and heavy cholesterol deposition (Fig. 23).

Eosinophilic granuloma. This may affect soft tissues or bone. The lesions are usually solitary, benign and easily treated by surgery, or X-ray therapy. Occasionally the lesions are multiple or diffuse and the condition is less easily distinguishable from the other varieties of histiocytosis X. As the name implies in addition to histiocytes the granulomatous lesions contain eosinophils in very large numbers.

\section{Tumours of bone}

Tumours of bone are relatively uncommon in children and only accounted for $3 \%$ of our material.

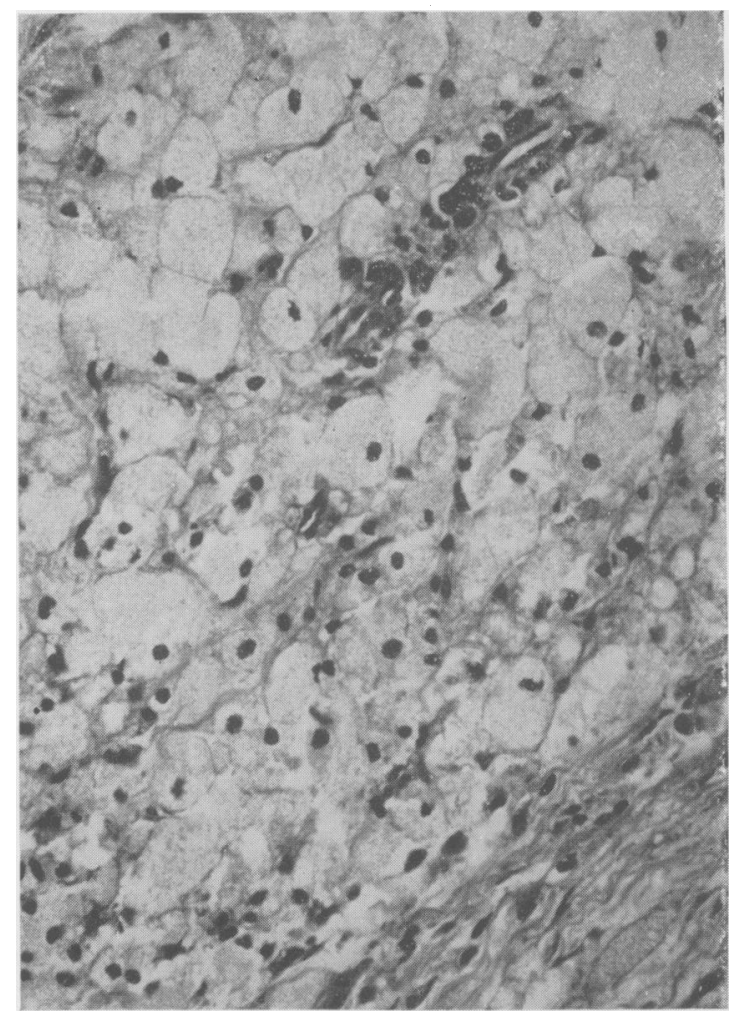

Fig. 23. H \& E. Hand-Schuller-Christian disease. Foamy histiocytes.

\section{(a) Benign tumours}

1. Osteoma. This lesion occurs mainly in membrane bone and may be found in the skull and facial bones. It is composed of bone lamellae covered by periosteum and occasional areas of compact bone. The tumour may become very hard and dense.

2. Osteoid osteoma. The lesion is usually small and is to be found in the cortex of long bones. There is a central mass of uncalcified trabeculae surrounded by sheets of osteoid tissue. The lesion may be extremely tender and painful. It is cured by surgical extirpation.

3. Osteochondroma. The lesions, which are exactly similar to those seen in multiple exostoses of hereditary origin, occur in the metaphyses of long bones. The outer part, which is covered by periosteum, is composed of cartilage which in turn lies over new bone.

\section{(b) Malignant tumours}

1. Osteogenic sarcoma. This is the most important of the malignant group of osseous tumours seen in children. It tends to affect the 10-15-year-olds rather than very young children and accounts for about one-sixth of malignant tumours in that age group.

The tumour arises towards the end of long bones, particularly around knee or shoulder. The tumour arises in the centre of the bone and rapidly penetrates the cortex and periosteum to form a bulbous mass around the end of the affected bone. On histological examination the cellular pattern may be varied but active bone formation is evident. The lesion is usually very cellular and multinucleated giant cells are not uncommon. Mitotic figures are numerous and considerable cell pleomorphism is observed. Metastases occur and the lung is a favourite site. The prognosis is bad, but a few children have been reported surviving after 10 years.

2. Ewing's tumour. Most round cell tumours of bone in children are examples of secondary deposits from a neuroblastoma. Occasionally, however, primary tumours of predominantly round cell type are seen in older children and young adults. They tend to occur in long bones, especially in the legs and are accompanied by pain and fever. The tumours have a greyish appearance when cut and areas of haemorrhage and necrosis are frequent. On histological examination the tumour is seen to be composed of sheets of round, darkly-staining cells with prominent nuclei and scanty cytoplasm. Metastases occur to regional lymph glands, lungs and other bones. The general pattern of the tumour is very similar to that of a reticulum cell sarcoma but silver stains fail to show evidence of reticulin formation.

The absence of a primary tumour elsewhere distinguishes the Ewing's tumour from the neuroblastoma. 
3. Chordoma. This is extremely uncommon in children. The tumour tends to arise at one or other end of the spinal column and forms a grey irregular mass. The latter is composed of huge, vacuolated cells with abundant cytoplasm and eccentric nucleithe so-called physaliferous cells. The tumours are, to some extent, radiosensitive, but the outlook is poor.

\section{Endocrine tumours}

\section{(a) Thyroid gland}

One of the few epithelial tumours to occur with any frequency in children is the carcinoma of the thyroid. These tumours have a variety of histological patterns. Some are markedly papillary in appearance, others are more solid and are composed of round or oval cells and still others show giant cell formation. The tumours tend to invade surrounding structures in the neck and the regional glands and to metastasize to the lung. Many metastases consist of well formed thyroid acini and may persist for years after removal of the primary tumour without apparently causing further invasion.

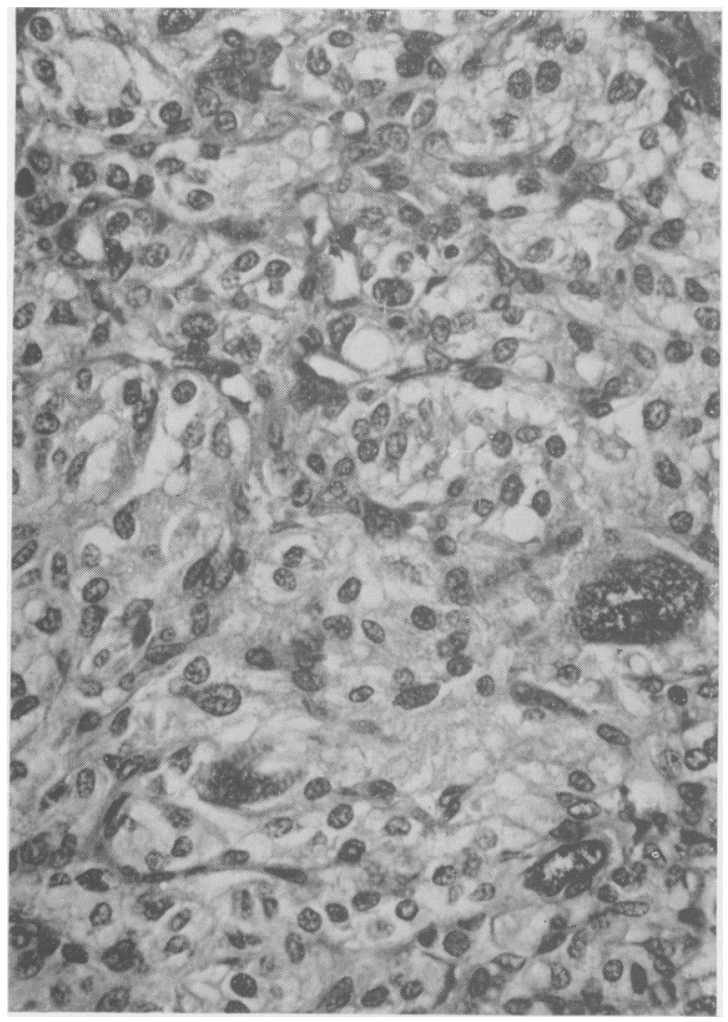

Fig. 24. Adrenal cortical adenoma showing marked pleomorphism.

\section{(b) Adrenal glands}

1. Cortical adenoma. This is the commonest of the adrenal cortical tumours in children. It may reach a considerable size and may be associated with Cushing's syndrome as a result of hyperadrenocorticisim. Not all examples of the latter are, of course, due to tumour formation and some may result from cortical hyperplasia.

The cellular pattern in adrenal cortical adenomas is extremely variable and bizarre cell forms are not unusual (Fig. 24).

2. Adrenocortical carcinoma. This is rare in children and is probably overdiagnosed on account of the bizarre histological pattern seen in many cortical adenomas. The tumour is histologically similar to the adenoma but is invasive and metastases occur. The latter are seen in regional nodes and in the lung.

3. Phaeochromocytoma. This tumour of the adrenal medulla is associated with adrenaline or noradrenaline secretion and gives rise to hypertension, sweating and polyuria. The tumours, which may be quite large, are often haemorrhagic or cystic. They have a yellow-brown colour and are composed of cords of large acidophil cells whose cytoplasm contains chromaffin granules (Fig. 25). The tumours may be benign or malignant.

4. Neuroblastoma. This common tumour of the adrenal medulla is described above.

\section{(c) Pituitary gland}

Tumours of the hypophysis are rare in children and the most frequent tumour of this region is the craniopharyngioma.

Adenomas of the pituitary, usually of the chromophobic variety, have been described in older children but the eosinophilic and basophilic adenomas are excessively rare.

\section{(d) Pineal gland}

The usual tumour is the pinealoma which is probably a form of teratoma. It is composed of sheets of relatively large cells interspersed by clumps of lymphocytes. The tumours are benign.

True teratomas, with a typical histological pattern also occur, especially in male children.

\section{(e) Thymus gland}

The thymoma is a tumour in which the cell component is that of the normal gland. In some cases it may be difficult to determine whether the lesion is a true tumour or whether the gland has undergone tremendous hyperplasia. The cells are usually small, 


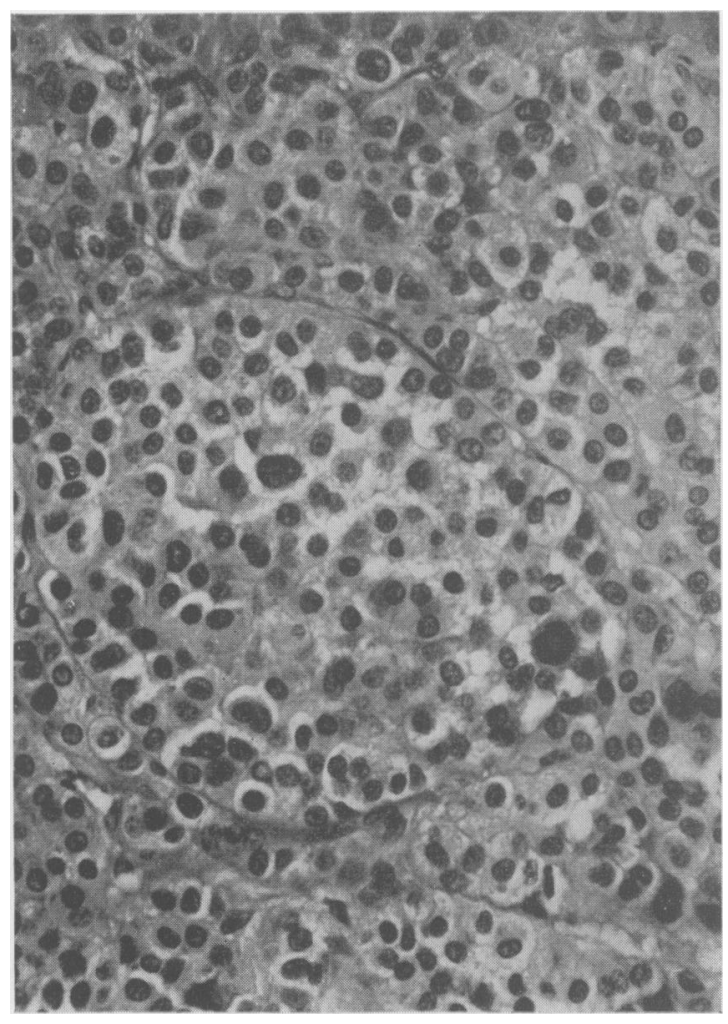

FIG. 25. H \& E. Suprarenal gland. Phaeochromocytoma. round, darkly-staining cells similar to the thymocyte Occasionally larger cells participate in the tumour formation and more rarely bizarre Hassall's corpuscles are identified. Metastases are uncommon.

A few cases of myasthenia gravis in children are associated with a thymoma.

The other tumour arising from the thymus, which may on occasion metastasize, is the teratoma.

\section{References}

Atwell, J.D., Claireaux, A.E. \& Nixon, H.H. (1967) Teratoma of the stomach in the newborn. Journal of Pediatric Surgery, 2, 197.

Bodian, M. \& White, L.L.R. (1952) Neoplastic diseases in childhood. Great Ormond Street Journal, 4, 105.

Claireaux, A.E. (1951) An intrapericardial teratoma in a newborn infant. Journal of Pathology and Bacteriology, 63, 743.

Claireaux, A.E. \& InNes-Williams, D. (1968) Tumours in children. In: Recent Advances in Surgery (Ed. by Selwyn Taylor). Churchill, London.

Nixon, H.H. (1965) Hepatic tumours in childhood and their treatment by major hepatic resection. Archives of Diseases of Childhood, 40, 167.

TAYLOR, C.W. (1968) Mesodermal mixed tumours of the female genital tract. Journal of Obstetrics \& Gynecology $65,177$.

Willis, R.A. (1962) The Pathology of the Tumours of Children Oliver and Boyd, Edinburgh.

Wilms, M. (1899) Die Mischgeschwulste der Niere. Georgi, Leipzig. 